\title{
GRACE hydrological monitoring of Australia: c urrent limitations and future prospects
}

\author{
J.L Awange (c orresponding author) \\ Westem Australian Centre for Geodesy \& The Institute for Geoscience Research, \\ Curtin University of Technology, GPO Box U1987, Perth WA 6845, Australia, E-mail \\ J.Awange@c urtin.edu.au; Tel +61 89266 7600; Fax +61 892662703
}

M.A. Sharifi

Geodetic Institute, Stuttga rt University, Gesc hwister-Sc holl-Strasse 24D, D-70174, Stuttgart, Germany, E-mail Sharifi@gis.uni-stuttgart.de; Tel +49 7116858 3393; Fax +49 71168583285 c urrent address?

\section{O. Baur}

Geodetic Institute, Stuttga it University, Geschwister-Sc holl-Stra sse 24D, D-70174, Stuttgart, Gemany, E-mail baur@gis.uni-stuttgart.de; Tel +49 7116858 4640; Fax +49 71168583285

W. Keller

Geodetic Institute, Stuttga rt University, Gesc hwister-Scholl-Stra sse 24D, D-70174, Stuttgart, Gemany, E-mail Keller@gis.uni-stuttgart.de; Tel +49 7116858 3459; Fax +49 71168583285

\section{W.E. Featherstone}

Westem Australian Centre for Geodesy \& The Institute for Geoscience Research, Curtin University of Tec hnology, GPO Box U1987, Perth WA 6845, Austra lia, E-mail W.Fea therstone@curtin.edu.au; Tel +61 89266 2734; Fax +61 892662703

\section{Kuhn}

Westem Australian Centre for Geodesy $\&$ The Institute for Geoscience Research, Curtin University of Technology, GPO Box U1987, Perth WA 6845, Australia, E-mail M.Kuhn@c urtin.edu.au; Tel +61 89266 7603; Fax +61 892662703

\begin{abstract}
The Gravity Recovery and Climate Experiment (GRACE) twin-satellite gravimetry mission has been monitoring time-varying changes of the Earth's gravitational field on a near-global scale since 2002. One of the environmentally important signals to be detected is temporal variations induced by changes in the distribution of terrestrial water storage (i.e., hydrology). Since water is one of Australia's precious resources, it is logical to monitor its distribution, and GRACE offers one such opportunity. We analyse the second and fourth releases (referred to as RLO2 and RL04) of the 'standard' monthly GRACE solutions with respect to their a nnual mean. When compared to rainfall data over the same time period, GRACE is shown to detect hydrological signals over Australia, with the RL04 data showing better results. However, the relatively small hydrological signal typical for much of Australia is obscured by deficiencies in the standard GRACE data processing and filtering methods. Spectral leakage of oceanic mass changes also still contaminates the small hydrological signals typical over land. We therefore recommend that Australia-focussed reprocessing of GRACE data is needed for useful hydrological signals to be extracted. Naturally, this will have to be verified by independent in situ extemal sources such as rainfall, soil moisture and groundwater borehole piezometer data over Australia.
\end{abstract}




\section{INTRODUCTION AND BACKGROUND}

The Gravity Recovery and Climate Experiment (GRACE) is a joint USGerman satellite mission dedicated to monitoring temporal and spatial variations in the Earth's extemal gravitational field on a near-global scale (e.g., Tapley et al., 2004a; 2004b; Wahr et al., 2004; Woodworth and Gregory, 2003; Rummel et al., 2002; Visser, 1999). This is done in a relatively cost-effective way by using two low-Earth orbiting (LEO) satellites operating in tandem (i.e., one following the other), coupled with precise orbit determination from a combination of the Global Positioning System (GPS) and inter-satellite K-band ranging.

As evidenced by much of the previous physical-geodetic research (e.g., Chao, 2003), the Earth's gravitational field has historically been treated as a largely static phenomenon, neglecting the albeit smaller temporal variations. For instance, AUSGeoid98 is assumed to be static, thus representing the gravity field as an average over the time the data used for its creation were collected (Featherstone et al., 2001).

Since the launch of the GRACE mission on 17 March 2002, it has become possible - for the first time - to monitor temporal variations in the Earth's extemal gravitational field on a near-global scale (e.g., Wahr et al., 2006; Riegger and Günter, 2004). GRACE allows these time-variations to be mapped every month (Luthcke et al., 2006) or less (e.g., Hu et al., 2006). While many factors cause the Earth's gravitational field to change with time, with tides being the most noticeable, another major factor is temporal variations in total terrestrial water storage, i.e., hydrology, on monthly timescales at spatial scales of the order of 1,000,000 km² (cf. Wahr et al., 1998).

Chen et al. (2006a) state that the GRACE mission duration has now been extended to 2010, extending its original five-yea r design life. In addition, plans are underway to launch a GRACE follow-on mission (R.S. Nerem, 2006 pers comm.), which will probably use lasers instead of K-band ranging, and thus improve the inter-satellite measurement accuracy from millimetres to microns, but the spatial resolution will probably not be improved much.

Numerous studies have demonstrated that GRACE can detect hydrological variations in major watersheds with active groundwater systems. Rodell and Famiglietti (1999) characterise water storage changes in 20 drainage basins of sizes varying from 130,000 km² to $5,782,000 \mathrm{~km}^{2}$ to assess detectability of hydrologic al signals with respect to temporal and spatial variations. Tapley $(2004 a, 2004 b)$ provide early results of the real applic ation of GRACE sa tellites to detect hydrological signals in the Amazon-Orinoco basin. Following the results of Tapley (ibid.), several other authors have subsequently applied GRACE to detect hydrologic al signals in va rious situations and locations.

For instance, Ramillien et al. (2004, 2005) and Andersen et al. (2005) consider global time variations of hydrological signals and 
variations of land-water storage from an inversion of two years of GRACE-derived geoids. Syed et al. (2005) examine total basin discharge for the Amazon-Orinoco and Mississippi river basins from GRACE and land-atmosphere water balance. Rodell et al. (2006) estimate groundwater storage changes in the Mississippi basin. Crowley et al. (2006) estimate hydrological signals in the Congo basin, while Schmidt et al. (2006b) and Swenson et al. (2003) use GRACE to observe changes in continental water storage. Awange et al. (2007) use GRACE to study the fall of Lake Vic toria's water level in Africa.

In Australia, Rodell and Famiglietti (1999) assess the detectability of variations in continental water storage from GRACE in the MurayDarling basin. Ellet et al. (2005) explore the potential of GRACE to assess large-scale hydrological models based on the simulation of Murray-Darling basin water storage for the period 2002-2003. Ellet et al. (2006) subsequently provide a framework for assessing the potential of GRACE to provide a new insight to the hydrology of the Murray-Darling basin.

Further examples of GRACE applic ation to monitoring terrestrial hydrological variations include, e.g., Seo and Wilson (2005), seo et al. (2006), Winsemius et al. (2006a; 2006b), Boy and Chao (2002), Hinderer et al. (2006), Lubes et al. (2004), Swenson et al. (2003), and Swenson and Milly (2006). Clearly, it is an ac tive a rea of study.

However, with the exceptions of Rodell and Famiglietti (1999) and Ellett et al. $(2005,2006)$, the above-cited studies have been conducted where hydrological signals (actually gravitational field signals due to changes in the mass of terrestrial water) a re large, which is not the case over most of Australia, especially in the current times of drought. Also, relatively less work has been done at smaller spatial scales (e.g., Swenson et al., 2006; Rodell and Famiglietti, 2001, 2005), principally due to the limited resolution of GRACE (because of the decrease in gravitational strength at the satellites' altitude), coupled with deficiencies in the data processing methods (disc ussed later).

This paper examines the current limitations of using GRACE to detect terrestrial water-mass variations over Australia from the 'standard' monthly gravity solutions (cf. Luthcke et al. 2006a). By 'standard', we mean that we use the fully nomalised spherical hamonic coefficients as provided by one GRACE-processing group, rather than processing the raw data ourselves. The former has proven to be particularly challenging because errors in the high-frequency (i.e., smaller scale) data from GRACE collude with the relatively small hydrological signal typical for much of Australia, making the hydrologic al component harder to detect from space.

However, based on many studies reported elsewhere (e.g., Beylkin and Cramer, 2004; Fengler et al., 2006; Han et al., 2005a; Lemoine et al., 2007; Schmidt et al., 2006a, 2006b, 2007; Rowlands et al., 2005; King et al., 2006; Bauer et al., 2007; Hu et al., 2006; Han et al., 2005c), there might be some scope for improved data processing and 
filtering techniques to be applied in an Australia-specific way to profit as much as possible from GRACE and its follow-on. By Australiaspecific, we mean that existing techniques should be adapted for the Australian situation, or new techniques that suit Austra lia be devised.

Essentially, we have now reached an era of environmental geodesy, where high-precision modem geodetic observations are helping scientists from many other disciplines to get a better understanding of the physics behind environmental change (e.g., Leuliette et al., 2002; Vespe and Rutigliano, 2005; Davis et al., 2004). A key example is monitoring contemporary deglaciation through observed changes in extemal gravitation (e.g., Baur et al., 2007; Kuhn et al. 2006; Frappart et al. 2006; Velicogna and Wahr 2005; Velicogna et al. 2005; Chen et al. 2006a, 2006b). The physical-geodetic contribution to hydrology is yet a nother example, shown here.

\section{KNOWN UMITATIONS OF GRACE}

In order to detect temporal gravitational variations at smaller spatial scales, the satellite(s) being tracked should be in as-low-as-possible orbits (close to the mass-change sources), with the proof masses in them being observed isolated, as-best-as-possible, from the perturbing effects of atmospheric drag.

LEO satellites have to be used for satellite gravimetry because of Newton's inverse square law of decay of the Earth's gravitational field with distance. The GRACE mission's altitude is $450 \mathrm{~km}$, which permits the reliable detection of gravity field changes to spherical hamonic degree -60 (Koch, 2005), corresponding to a spatial resolution of -660 $\mathrm{km}$ (or $\sim 330 \mathrm{~km}$ half-wavelength) at the equator.

La rge time-varying gravitational signals, notably variations due to atmosphere- and ocean-mass tides, have to be removed during the processing of GRACE data so that the mission reveals time variations of hydrological, or other, interest. These de-aliasing models (for correcting short term; e.g., six-hour for tidal variations) have to be used to mitigate the propagation of spurious signals into the GRACE solutions (e.g., Han et al., 2004; Flechtner et al., 2006; Schrama and Visser, 2007; Knudsen and Andersen, 2002). However, these de-aliasing models are not perfect, so some spectral leakage and aliasing still remains in the GRACE solutions.

Probably the largest problem in GRACE solutions is that some of them are plagued with striping, where dominantly north-south strips associated with the GRACE satellite ground tracks tend to dominate the high-frequency component of the GRACE-derived gravitational signal (see, e.g., Fig. 9 in Tapley et al., 2005). There remains some conjecture as to the exact cause of the striping, but it is thought to be mostly due to too much weight being placed on the along-track Kband ranging data (e.g., Swenson and Wahr 2006; Schrama and Visser 2007), coupled with inaccurate de-aliasing models and the mission configuration. 
Other GRACE errors relate to spectral leakage from time-varying ocean-based masses, which propagate spatially to mask any weak hydrological signals of interest (shown later). Finally, Chen et al. (2006c), among many others, point out that the high-degree and order spherical harmonics of GRACE time-variable gravitational field models are dominated by noise.

\section{CURRENTGRACE CONIRIBUTION TO AUSTRALAN HYDROLOGY}

The application of GRACE to monitoring hydrological variations works well (i.e., in terms of spatial resolution of the signal that can be detected) for a global model (e.g., Wu et al., 2006; Andersen and Hinderer, 2005) or for very large scale/volume drainage basins such as the Amazon, Mississippi, Ganges and Zambezi. Rodell and Famiglietti (2001) recommend basin sizes greater than $200,000 \mathrm{~km}^{2}$ (e.g. $-450 \mathrm{~km} x$ $-450 \mathrm{~km}$ ) for a precision of a few $\mathrm{mm}$ in equivalent water thickness (EWT) derived from GRACE. In terms of GRACE hydrology, the gravitational field data are routinely converted into units of $\mathrm{mm}$ of EWT using the algorithms in Wahret al. (1998).

More recent studies (e.g., Smith et al. 2005) indic ate that an area of at least 500,000 km² (e.g. $\sim 700 \mathrm{~km} \mathrm{x} 700 \mathrm{~km}$ ) and a time-period of one month are required for better EWT estimates. Areas of smaller spatial extent suffer from increased noise in high degrees and orders and spectral leakage of the gravitational effects from surrounding masses (Han et al. 2006), notably the oceans. Therefore, for efficient monitoring of Australia's stored water, two key issues emerge:

1. A desire to have a higher temporal resolution than the 30-day 'standard' GRACE data processing epochs (cf. Luthcke et al. 2006). If the variation in water-mass can be known sub-monthly rather than monthly, this would greatly enhance water management issues in Australia (cf. Hu et al. 2006).

2. A desire to exploit GRACE data to provide hydrological variations at higher spatial resolutions so as to cater for smaller basins and freshwater aquifers of less than $200,000 \mathrm{~km}^{2}$ in area, which is the case formost of Australia.

Whereas GRACE-monitoring of stored water has been successfully tested for and applied to very large/volume drainage basins, as discussed earlier, the Australian case presents a more complicated scenario due, largely, to spectral-leakage contamination from oceanic mass-change signals coupled with the relatively small hydrological signal that is typical over most of Australia. As will be shown later, spectral leakage from the oceans obscures the land hydrological signal, sometimes for a considerable distance.

The current Australian drought has both positive and negative effects on the application of GRACE to Australian hydrology. On the positive side, it provides the opportunity for the application of GRACE to measure how Australia has dried out in the last five years and study whether ra infall actually replenishes the water supply. On the negative 
side, the hydrological signals may have become too weak to be detected using 'standard' GRACE processing methods. Nevertheless, GRACE could be used to study variations in stored water over Australia, provided that data emrors are reduced through proper filtering and data processing techniques.

Finally, the 'standard' monthly GRACE gravity field solutions are expressed in terms of fully nomalised spherical harmonics, which are globally supported basis functions (cf. Bla is and Provins, 2002). Spherical hamonics are the standard for representing the global extemal gravitational field. However, they a re oscilla tory functions that depend on superposition cancellation and addition to represent local features. In principle, there is a global mapping between every observation and every coeffic ient (e.g., Moritz, 1980; Colombo, 1989; Pavlis et al., 1996). This makes it diffic ult, if not impossible, to a djust the spatial frequency contents loc ally (i.e., using global spheric al ha monic models for local mapping). While Chen et al. (2007) have used basin functions to try to mitigate this problem, they acknowledge that it is imperfect and still permits spectral leakage.

As such, it is also important to seek altemative representations of the Earth's extemal gravitational field that allow localised studies to be conducted from GRACE, and that they are not contaminated by data or mis-modelling errors from other areas. Some potential candidates will be disc ussed later.

\section{Australia-wide hydrology}

To indicate the capability of GRACE to monitor stored water over Australia, two data sets, namely RLO2 (released in 2006) and RL04 (released in May 2007), will be used to compute hydrological signals (EWT) over Australia for the year 2004 as an example. The purpose of using these two releases is to assess any improvement in release RL04 compared to RL02 in the Australian context. We use the 'standard' monthly GRACE solutions published by the Center for Space Research (CSR) at the University of Texas at Austin, USA, (http://www.csr.utexas.edu/grace/) to generate EWT for Australia from the Wahr et al. (1998) algorithm.

We acknowledge that other GRACE solutions are published by other groups; these being GFZ (GeoForschungZentrum, Germany), JPL (J et Propulsion Laboratory, USA) and GRGS (Groupe de Recherche de Géodésie Spatiale, France). We chose the RL02 and RL04 CSR solutions mainly for reasons of convenience, but also to exemplify some of the problems with GRACE-based hydrology in Australia. As such, the comments and approaches in this paper apply to the CSR solutions only, and not all other GRACE solutions from other groups.

The monthly spherical hamonic coefficients are computed relative to the annual mean (i.e., coeff $=$ coeff(month) - coeff(annual mean)) for each month during 2004 as a typical example. The correlated-error filter proposed by Swenson and Wahr (2006) was applied to the 
'standard' monthly spherical harmonic coefficients from CSR, followed by smoothing using a Gaussian filter of radius $500 \mathrm{~km}$. The filtering and smoothing reduce the south-north striping effects, which had previously made the detection of hydrological signals over Australia extremely diffic ult from RL02 of the CSR solutions. Recall that the need to apply Gaussian filtering is not always necessary for other GRACE models (cf. Lemoine et al., 2007).

Figures 1 and 2 show EWT computed from RL02 and RL04 respec tively. Although most months show some similarities, August and September in 2004 show RL04 to be smoother than RL02, indicating the improved data processing techniques used in RL04. The most discemible EWT signals occur in northem Australia duning February, March and April 2004, which are sub-tropical regions that often experience heavy rainfall during these months.

Comparison between GRACE signals (Fig. 2) and rainfall data for the same months in 2004 (Fig. 3) shows quite a good spatial correlation between the high rainfall in February (more than $300 \mathrm{~mm}$ ) with the GRACE hydrological signals for the same month. The monthly rainfall data were provided by the Australian Bureau of Meterology (cf. J ones and Weymouth, 1997), and have been generated using Bames's (1994a,b,c) succ essive correction technique, which applies a weighted average to data reported within set grids across Australia (see, e.g., http://www.bom.gov.au/climate/austmaps/ma pinfo.shtml\#va riables).

In order to be more consistent with the GRACE data presentation (Figures 1 and 2), the monthly rainfall variations in Figure 3 are computed relative to the annual mean (i.e., monthly total minus annual mean) for each month during 2004 . It is important to acknowledge that a one-to-one correlation can never be expected from such a companison (i.e., GRACE versus ra infall) because of many other factors that affect the mass-transport of terrestrial water. For instance, evapotranspiration and the rates of rainfall run-off will affect their temporal and spatial correlation. Nevertheless, we offer a firstlook a nalysis of what may be the major signals.

In Figure 3, May 2004 shows hydrological signals in central Australia. These signals are detected by the GRACE satellites in the subsequent two months of J une and J uly. From J une to August, the Murray-Darling basin contains signals that are detected by GRACE in August and September (Figure 2). These examples indicate that the rainfall water has been retained for two months following the rains before being detected by GRACE. Such information may be relevant for water resource management and policy makers. 



Figure 1. Monthly va riations (in $\mathrm{mm}$ ) of EWT from the mean over Austra lia in 2004 from CSR's GRACE relea se RL02 data (Lambert projection). 

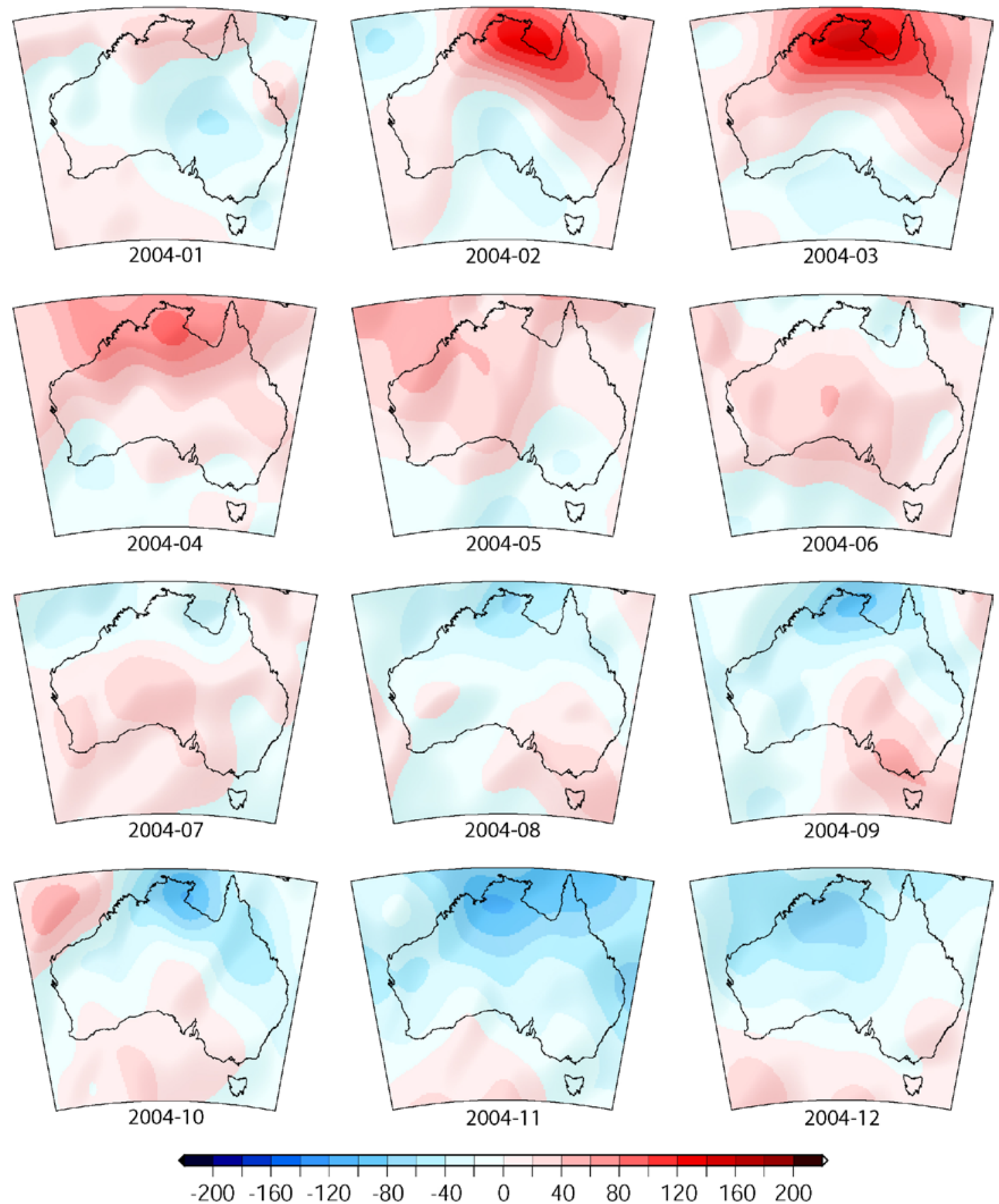

Figure 2. Monthly va riations (in $\mathrm{mm}$ ) of EWT from the mean over Australia in 2004 from CSR's GRACE relea se RL04 data (Lambert projection). 

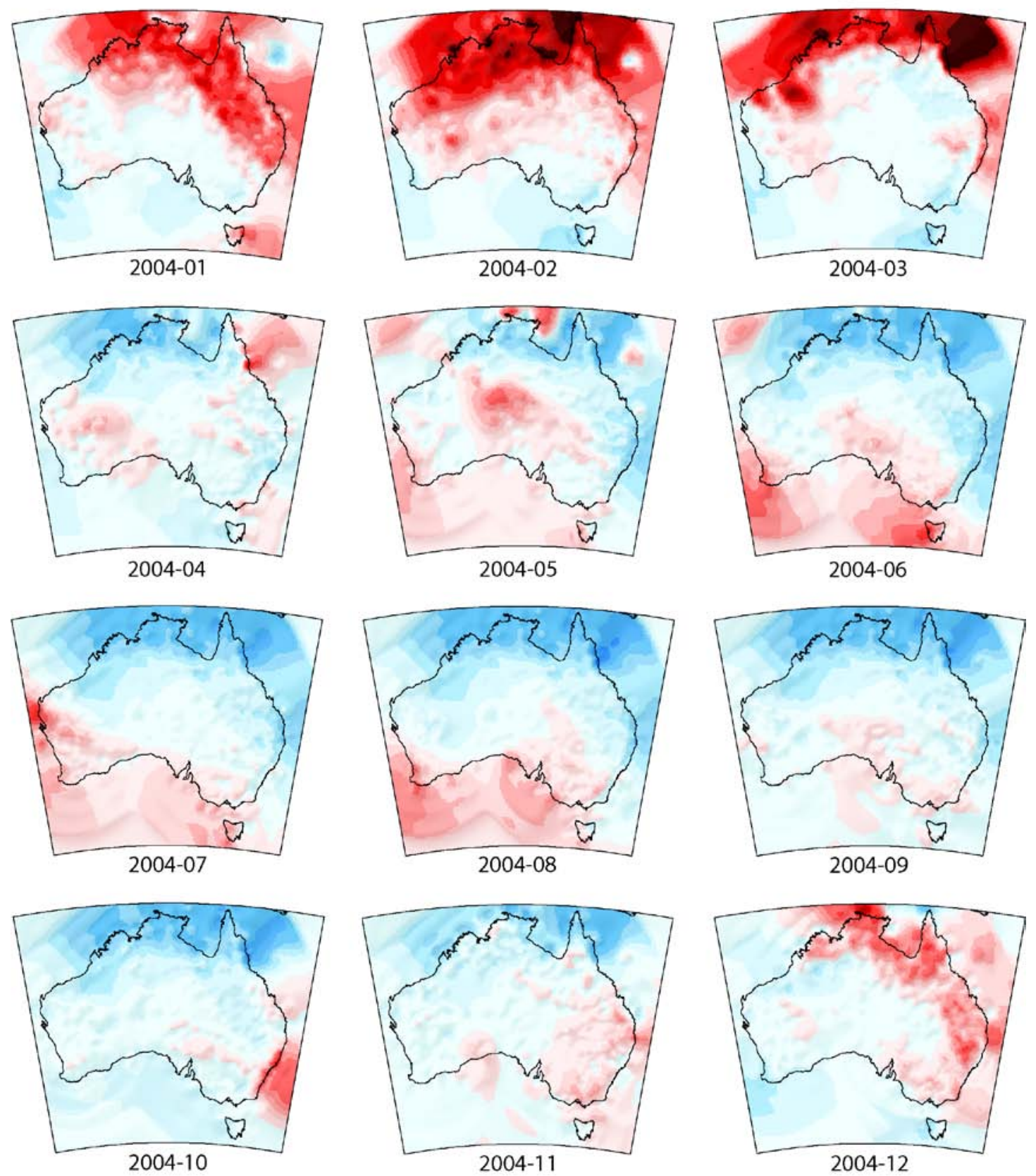

$$
-400-300-200-100-50 \quad 0 \quad 50100200300400
$$

Figure 3. Monthly ra infall va riations (in $\mathrm{mm}$ ) from the mean over Australia in 2004 from Bureau of Meteorology ra infall data (Lambert projection)

While the signals discussed above are detectable by GRACE, weaker signals (e.g., April in Figure 3) are masked/obscured by spectral leakage, even in the RL04 data (Figure 2). This spectral leakages from ocean water-mass changes are dominant in April, May, June, November and December (Figure 2). This shows that ocean watermass changes have not been modelled correctly, especially in the geodetically problematic coastal zone (cf. Deng and Featherstone, 2006). Therefore, improved filtering techniques are needed to remove a lia sing (Han et al., 2004; Flechtner et al., 2006; Thompson et al., 2004), 
and spectral leakage from the oceans (cf. Chen et al., 2006c).

\section{DISCUSSION}

The first-look results here show the potential for Australian hydrology to be monitored using GRACE, but only now for the improved CSR RL04 data that have been filtered and Gaussian-smoothed. The fact that some of the monsoonal seasons in the north of Australia appear in the GRACE data indicate that temporal and spatial variations in terrestrial water can indeed be detected from space. Also, the Murray-Darling basin has an area of $1,061,469 \mathrm{~km}^{2}$, which is much greater than the $200,000 \mathrm{~km}^{2}$ to $500,000 \mathrm{~km}^{2}$ areas used in other studies elsewhere. However, hydrological signals likely in the Murray-Darling basin are much smaller than in other major drainage basins around the world (e.g., Amazon, Mississippi, Ganges and Zambezi). Nevertheless, there appears to be some modest amount of variability in and a round the Murray-Darling basin detected from GRACE, which is encouraging (e.g., Figure 3 for September).

As opposed to large basins, signific ant water 'users' in Australia, e.g., farmers in the south-westem Australian wheat-belt region or managers of freshwater aquifers all over Australia, are usually interested in water variation at much higher spatial resolution (e.g., $\sim 200 \mathrm{~km} \times \sim 200 \mathrm{~km}$ ) than can be resolved by the CSR 'standard' monthly GRACE solutions. However, given the ultimate limitation of GRACE and GRACE follow-on missions imposed by atmospheric drag, satellite gravimetry will possibly never deliver detailed hydrological data at such small scales. Nevertheless, it is important to 'push the boundaries' to gain the most information from satellite-based hydrology.

In order to obtain any higher spatial resolution, more robust mathematical approaches that are applicable to small-scale hydrological mapping need to be investigated. Several procedures have been proposed and tested in other a reas that could possibly be used in Australia to achieve higher spatial (less than 200,000km²) and temporal (sub-monthly) resolution hydrological va riations from GRACE. Options include the wavelet approach (Beylkin and Cramer 2004; Fengler et al. 2006; Schmidt et al. 2006a), regional inverse method (Han et al. 2005b) and mascons (Lemoine et al. 2007). Importantly, these methods avoid the spherical hamonic approach, thus allowing better space-localisation. Indeed, there may be other approaches currently being developed, or ones that we can devise here in Australia.

Therefore, there is a need to analyse more robust method(s) that will better exploit GRACE data and provide timely small-scale variations in stored water over a short time frame (cf. Rowlands et al. 2005).

\section{CONCWSONS AND RECOMMENDATIONS}

From the 'standard' monthly GRACE solutions from CSR, even for the more recent RLO4 data release, there is considerable influence of interfering effects such as GRACE de-aliasing errors and spectral 
leakage that we attribute to ocean-mass variations. These impede the reliable detection of the relatively small hydrological signals expected in Australia. This is especially the case because it is the driest continent, and has been experiencing serious drought in many regions during the lifetime of the GRACE mission.

There is therefore need to investigate and apply Australia-specific techniques to better-estimate small hydrological signals from GRACE. The fundamental tasks required that we recommend are:

- Analysis of wavelet, regional inversion and mascon methods to establish if any best fits Australia, coupled with a search for any new Australia-spec ific method;

- Development, refinement and in-situ testing of whichever method selected from above to improve its capability for Australia;

- Application of the new method(s) to reprocess GRACE data to provide timely variations in Australia's stored water at both small and large scales to within, say, 14 days or less.

Acknowledgements: The embryonic parts of this project were disc ussed while WEF was a $n$ Alexander von Humboldt Fellow at Stuttgart University, Germany, during 2006, where WK, JLA, MS and OB were at that time. WEF gratefully acknowledges generous funding from the Alexander von Humboldt Stiftung through a ward 1120942. WEF is also funded by Australian Research Council grant DP0663020. J LA and WEF would also like to thank M. Dolling, Landgate, P. Commander and G. Humphries, Westem Australian Department of Water, and R. Vogwill, Westem Australian Department of Conservation and Land Management, for discussions on this fea sibility study in the Westem Australian context. Finally, thanks a re extended to the editors (G. Wright and P. Collier) and reviewers ( $P$. Tregoning and $M$. Walker) of this manuscript. This is The Institute for Geosc ience Resea rch (TIGeR) public ation number 85.

\section{REFERENCES}

Andersen, O.B. and Hinderer, J. (2005) Global inter-annual gravity changes from GRACE: Early results. Geophysical Research Letters, vol. 32, article L1402, DOI: 10.1029/2004G L020948

Andersen, O.B., Seneviratne, S.I., Hinderer, J., and Viterbo, P. (2005) GRACEderived terrestrial water storage depletion associated with the 2003 European heat wave. Geophysic al Research Letters, vol. 32, a rtic le L18405, DOI: 10.1029/2005GL023574

Awange, J.L., Sharifi, M.A., Ogonda, G., Wickert, J., Grafarend, E.W. and Omulo, M. (2007) The Falling Lake Victoria Water Levels: GRACE, TRIMM and CHAMP satellite analysis of the lake basin. Water Resource Management . DOI 10.1007/s11269-007-9191-y

Bames, S.L. (1994a) Applications of the Bames objec tive a nalysis scheme. Pa rt 1: effects of under sampling, wave position and station randomness, J oumal of Atmospheric and Oceanic Technology, vol. 11, no. 6, pp. 14331448, doi: 10.1175/1520-0426(1994)011<1433:AOTBOA>2.0.CO;2

Bames, S.L. (1994b) Applications of the Bames objec tive a nalysis scheme. Pa rt 2: Improving deriva tive estimates. Joumal of Atmospheric and Oceanic 
Technology, vol. 11, no. 6, pp. 1449-1458, doi: 10.1175/15200426(1994)011<1449:AOTBOA>2.0.CO;2.

Bames, S.L. (1994c) Applic ations of the Bames objec tive a na lysis sc heme. Part 3: Tunning for minimum error. J oumal of Atmospheric and Oceanic Technology, vol. 11, no. 6, pp. 1459-1479, doi: 10.1175/15200426(1994)011<1459:AOTBOA>2.0.CO;2.

Bauer, F., Mathe, P. and Pereverzev, S. (2007) Local solutions to inverse problems in geodesy. Joumal of Geodesy, vol. 81, no. 1, pp. 39-51, DOI: 10.1007/s00190-006-0049-5

Baur, O., Kuhn, M. and Featherstone, W.E. (submitted September 2007) GRACE-derived ice-mass variations and their effect on global sea-level change pattems, J ournal of Geophysical Research - Solid Earth

Beylkin, G. and Cramer, R. (2004) Towards multiresolution estimation and efficient representation of gravitational fields. Celestial Mechanics and Dynamics Astronomy, vol. 84, no. 1, pp. 87-104, DOI: 10.1023/ A:1019941111529

Bla is, J .A.R. and Provins, D.A. (2002) Spheric al harmonic a nalysis and synthesis for global multiresolution applications. Joumal of Geodesy, vol. 76, no. 1, pp. 29-35, DOI: 10.1007/s001900100217

Boy, J-P. and Chao, B.F. (2002) Time-variable gravity signal during the water impoundment of China's Three-Gorges Reservoir. Geophysical Research Letters, vol. 29, a riticle 2200, DOI:10.1029/2002G L016457

Chao, B.F. (2003) Geodesy is not just for static mea surements any more. EOS Transactions of the American Geophysical Union, vol. 84, pp. 145-150, DOI: 10.1029/2003EO 160001

Chen, J.L., Tapley, B.D., and Wilson, C.R. (2006b) Alaskan mounta in glacial melting observed by satellite gravimetry. Earth and Planetary Science Letters, vol. 248, pp. 368-378, DOI: 10.1016/j.epsl.2006.05.039

Chen, J.L., Wilson, C.R., and Seo, K-W. (2006C) Optimized smoothing of Gravity Recovery and Climate Experiment (GRACE) time-variable gravity observations. Joumal of Geophysical Research (Solid Earth), vol. 111, no. B10, a rticle B06408, DOI: 10.1029/2005J B004064

Chen, J.L., Wilson, C.R., Blankenship, D.D., and Tapley, B.D. (2006a) Anta rctic mass rates from GRACE. Geophysical Research Letters, vol. 33, article L11502, DOI:10.1029/2006GL026369

Chen, J.L, Wilson, C.R., Famiglietti, J.S. and Rodell, M (2007) Attenuation effect on seasonal basin-scale water storage changes from GRACE timevariable gravity. Joumal of Geodesy, Vol. 81, No. 4, pp. 237-245 10.1007/s00190-006-0104-2

Colombo, O. (1989) Advanced techniques for high-resolution mapping of the gravita tional field, in Sansó, F. and Rummel, R. (eds.), Lecture Notes in Earth Sciences, vol. 25, Springer, Berlin Heidelberg New York, pp. 335-369.

Crowley, J .W., Mitrovic a, J .X., Ba iley, R.C., Tamisiea, M.E., and Davis, J.L. (2006) Land water storage within the Congo Basin inferred from GRACE satellite gravity data. Geophysical Research Letters, vol. 33, article L19402, DOI: 10.1029/2006G L027070

Davis, J.L., Elósegui, P., Mitrovica, J.X., and Tamisiea, M.E. (2004) Climatedriven deformation of the solid Earth from GRACE and GPS. Geophysical Research Letters, vol. 31, a rtic le L24605, DOI: 10.1029/2004GL021435

Deng, X.L. and Featherstone, W.E. (2006) A coastal retracking system for satellite radar altimeter waveforms: application to ERS-2 a round Australia, 
Joumal of Geophysical Research (Oceans), vol. 111, article C06012, doi: 10.1029/2005] C 003039

Ellett, K. M., Walker J. P., Rodell M., Chen J.L., and Westem A. W. (2005) GRACE gravity fields as a new measure for assessing large-scale hydrological models. In A. Zerger and R. M. Argent (Eds). Modell. and Simul. Soc. of Aust. and N. Z, December 2005, pp. 2911 - 2917, ISBN: 0-9758400-29.

Ellett, K. M., Walker J. P., Westem A. W., and Rodell M. (2006) A framework for assessing the potential of remote sensed gravity to provide new insight on the hydrology of the Muray-Darling Basin. Australian Joumal of Water Resources, vol. 10, no. 2, pp. 89-101.

Fea therstone, W.E., J .F. Kirby, A.H.W. Kearsley, J.R. Gilliland, G.M. J ohnston, J . Steed, R. Forsberg, M.G. Sideris (2001) The AUSGeoid98 geoid model of Australia: data treatment, computations and comparisons with GPSlevelling data. Joumal of Geodesy, vol. 75, no. 5-6, pp. 313-330, DOI: $10.1007 /$ s001900100177.

Fengler, M.J., Freeden, W., Kohlhaas, A., Michel, V. and Peters, T. (2006) Wavelet modelling of regional and temporal variations of the Earth's gravitation potential observed by GRACE. J oumal of Geodesy, vol. 81, no. 1, pp. 5-15, DOI 10.1007/s00190-006-0040-1

Flechtner, F., Schmidt, R., and Meyer, U. (2006) De-aliasing of short-term atmospheric and oceanic mass variations for GRACE, In Flury, J ., Rummel, R., Reigber, C., Rothacher, M., Boedecker, G., and Schreiber, U. (Eds), Observation of the Earth System from Space, Springer, Berlin Heidelberg New York, pp. 83-97.

Frappart, F., Ramillien, G., Bia ncamaria, S., Mognard, N.M., and Cazenave, A. (2006) Evolution of high-latitude snow mass derived from the GRACE gravimetry mission (2002-2004). Geophysical Research Letters, 33:2501-+, doi:10.1029/2005GL024778.

Han, S-C., J ekeli, C., and Shum, C.K. (2004) Time-variable aliasing effects of ocean tides, atmosphere, and continental water mass on monthly mean GRACE gravity field. Joumal of Geophysical Research (Solid Earth), vol. 109, no. B18, article B04403, DOI: 10.1029/2003J B002501.

Han, S-C., Shum, C. K., and Jekeli, C. (2006) Precise estimation of in situ geopotential differences from GRACE low-low satellite-to-satellite tracking and accelerometer data. Joumal of Geophysical Research (Solid Earth), vol. 111, no. B10, a rticle B04411, DOI:10.1029/2005J B003719.

Han, S-C., Shum, C.K., and Braun, A. (2005b) High-resolution continental water storage recovery from low-low satellite-to-satellite tracking. Joumal of Geodynamic S, vol. 39, no. 1, pp. 11-28

Han, S-C., Shum, C.K., Jekeli, C., Kuo, C-Y., Wilson, C., and Seo, K-W. (2005C) Non-isotropic filtering of GRACE temporal gravity for geophysical signal enhancement. Geophysic al J oumal Intemational, vol. 163, no. 1, pp.18-25, DOI:10.1111/j.1365-246X.2005.02756.X.

Han, S-C., Shum, C-K., Jekeli, C. and Alsdorf, D. (2005a) Improved estimation of terrestrial water storage changes from GRACE. Geophysical Research Letters, vol. 32, article L07302, DOI 1029/2005G L022382

Hinderer, J ., Andersen, O., Lemoine, F., Crossley, D., and Boy, J .P. (2006) Seasonal changes in the European gravity field from GRACE: A comparison with superc onducting gravimeters and hydrology model predic tions. 
J oumal of Geodyna mics, vol. 41, no. 1, pp. 59-68, DOI: 10.1016/j.jog.2005.08.037

Hu, X., Shi, C., Flechtner, F., König, R., Schwintzer, P., Schmidt, R., Meyer, U., Massmann, F. H., Reigber, Chr., and Zhu, S. (2006) High frequency temporal Earth gravity variations detected by GRACE satellites. In Flury, J., Rummel, R., Reigber, C., Rotha cher, M., Boedecker, G., and Schreiber, U. (Eds.), Observation of the Earth System from Space, Springer, Berlin Heidelberg New York, pp. 165-174.

Jones, D. and Weymouth, G. (1997) An Australia n monthly rainfall data set. Technic al Report 70, Bureau of Meteorology, Melboume, Australia, 19pp.

King, M., Moore, P., Clarke, P., and Lavallée, D. (2006) Choice of optimal averaging radii for temporal GRACE gravity solutions, a comparison with GPS and satellite altimetry. Geophysical J oumal Intemational, vol. 166, no. 1, pp. 1-11, DOI: 10.1111/j.1365-246X.2006.03017.x

Knudsen, P. and Andersen, O.B. (2002) Correcting GRACE gravity fields for ocean tide effects. Geophysical Research Letters, vol. 29, no. 8, 1178, DOI:10.1029/2001GL014005.

Koch, K-R. (2005) Determining the maximum degree of hamonic coefficients in geopotential models by Monte Carlo methods, Studia Geophysica et Geodaetica, vol. 49, no. 3, pp. 259-275, doi: 10.1007/s11200-005-0009-1

Kuhn, M. Featherstone, W.E., Makarynskyy, O. and Keller, W. (2006) When the Ice Melts. Position Magazine, vol. 23, pp. 23-25.

Lemoine, F.G., Luthcke, S.B., Rowlands, D.D., Chinn, D.S., Klosko, S.M. a nd Cox, C.M. (2007) The use of Mascons to resolve time variable gravity from GRACE. In: Tregoning, P and Rizos, C. (Eds) Dynamic Planet: Monitoring and understanding a dynamic planet with geodetic and oceanographic tools, Springer, Berlin Heidelberg New York, pp. 231-236

Lemoine, J-M., Bruinsma, S., Loyer, S., Biancale, R., Marty, J-C., Perosanz, F. and Balmino, G. (2007) Temporal gravity field models inferred from GRACE data, Advances in Space Research, Vol. 39, No. 10, pp. 1620-1629, doi:10.1016/j.asr.2007.03.062

Leuliette, E.W., Nerem, R.S., and Russell, G.L. (2002) Detecting time variations in gravity associated with climate change. Joumal of Geophysical Research (Solid Earth), vol. 107, vol. 107, no. B6, DOI 10.1029/2001J B000404

Lubes, M., Florsch, N., Hinderer, J ., Longuevergne, L., and Amalvict, M. (2004) Local hydrology, the Global Geodynamics Project and CHAMP/GRACE perspective: some case studies. Joumal of Geodynamics, vol. 38, no. 3-5, pp. 355-374. DOI: 10.1016/j.jog.2004.07.015

Luthcke, S.B., Rowlands, D.D., Lemoine, F.G., Klosko, S.M., Chinn, D., and McCarthy, J.J. (2006) Monthly spherical hamonic gravity field solutions determined from GRACE inter-satellite range-rate data alone. Geophysical Research Letters, vol. 33, artic le L2402, DOI: 10.1029/2005G L024846

Moritz H (1980) Advanced Physical Geodesy, Wic hmann, Ka rsruhe, Germa ny.

Pavlis, N.K., Chan, J.C. and Lerch, F.J . (1996) Altema tive estimation techniques for global high-degree gravity modeling, In: Rapp, R.H., Cazenave, A.A and Nerem, R.S. (Eds.) Global Gravity Field and Its Temporal Variations, Springer, Berlin Heidelberg New York, pp 111-120

Ramillien, G., Cazenave, A., and Brunau, O. (2004) Global time va riations of hydrological signals from GRACE satellite gravimetry. Geophysical J oumal Intemational, vol. 158, no. 3, pp. 813-826, DOI: $10.1111 /$ j.1365246X.2004.02328.x 
Ramillien, G., Frappart, F., Cazenave, A., and Güntner, A. (2005) Time variations of land water storage from an inversion of two years of GRACE geoids [rapid communication]. Earth and Planetary Science Letters, vol. 235, no. 1-2, pp. 283-301, DOI: 10.1016/j.epsl.2005.04.005.

Riegger, J. and Güntner, A. (2004) Time variation in hydrology and gravity. Earth Moon and Planets, vol. 94, no. 1, pp. 41-55, DOI: 10.1007/s11038-0051831-8

Rodell, M. and Famiglietti, J.S. (1999) Detectability of variations in continental water storage from satellite observations of the time dependent gravity field. Water Resources Research, vol. 35, no. 9, pp. 2705-2724, DOI: 10.1029/ 1999WR900141

Rodell, M. and Famiglietti, J.S. (2001) An analysis of terrestrial water storage variations in Illinois with implic ations for the Gravity Recovery and Climate Experiment (GRACE). Water Resources Research, vol. 37, no. 5, pp. 13271340, DOI: 10.1029/2000WR900306

Rodell, M. and Famiglietti, J.S. (2005) Terrestrial water storage variations over Illinois: analysis of observations and implications for GRACE. Water Resources Resea rch, vol. 37, no. 5, pp. 1327-1340.

Rodell, M., Chen, J., Kato, H., Famiglietti, J.S., Nigro, J., and Wilson, C.R. (2006) Estimating groundwater storage changes in the Mississippi River ba sin (USA) using GRACE. Hydrogeology J oumal, vol. 15, no. 1, pp. 159-166, DOI:10.1007/s10040-006-0103-7

Rowlands, D.D., Luthcke, S.B., Klosko, S.M., Lemoine, F.G., Chinn, D.S., McCarthy, J J., Cox, C.M., and Anderson, O.B. (2005) Resolving mass flux at high spatial and temporal resolution using GRACE intersatellite measurements. Geophysical Research Letters, vol. 32, article L4310, DOI: 10.1029/2004G L021908

Rummel, R., Ba Imino, G., J ohannessen, J ., Visser, P., a nd Woodworth, P. (2002) Dedicated gravity field missions - principles and aims. Joumal of Geodynamics, vol. 33, no. 1, pp. 3-20, DOI: 10.1016/S0264-3707(01)00050-3

Schmidt, M., Han, S.-C., Kusche, J., Sanchez, L, and Shum, C.K. (2006a) Regional high-resolution spatiotemporal gravity modeling from GRACE data using spherical wavelets. Geophysical Research Letters, vol. 33, a rticle L08403, DOI: 10.1029/2005GL025509

Schmidt, R., Schwintzer, P., Flechtner, F., Reigber, C., Güntner, A., Döll, P., Ramillien, G., Cazenave, A., Petrovic, S., Jochmann, H., and Wünsch, J. (2006b) GRACE observations of changes in continental water storage. Global and Planetary Change, vol. 50, no. 1-2, pp. 112-126

Schrama, E.J.O. and Visser, P.N.A.M. (2007) Accuracy assessment of the monthly GRACE geoids based upon a simulation. Joumal of Geodesy, vol. 81, no. 1, pp. 67-80, DOI: 10.1007/s00190-006-0085-1

Seo, K-W. and Wilson, C.R. (2005) Simulated estimation of hydrological loads from GRACE. Joumal of Geodesy, vol. 78, no. 5, pp. 442-456, DOI: 10.1007/s00190-004-0410-5

Seo, K-W., Wilson, C.R., Famiglietti, J.S., Chen, J.L., and Rodell, M. (2006) Terrestrial water mass load changes from Gravity Recovery and Climate Experiment (GRACE). Water Resources Research, vol. 42, article W05417, DOI: 10.1029/2005WR004255

Smith A. B., Walker J.P., Westem A.W. and Ellet K.M., (2005) Using groundbased gravity measurements to monitor changes in terrestrial water storage. Engineers Australia 29th Hydrology and Water Resource 
Symposium, 21-23 February 2005, Ca nberra, Austra lia.

Swenson, S. and Wahr, J. (2006) Post-processing removal of correlated errors in GRACE data. Geophysical Research Letters, vol. 33, article L08402, DOI: 10.1029/2005G L025285.

Swenson, S., Wahr, J., and Milly, P.C.D. (2003) Estimated accuracies of regional water storage variations inferred from the Gravity Recovery and Climate Experiment (GRACE). Water Resources Research, vol. 39, no. 8, article 1223, DOI: 10.1029/2002WR001736.

Swenson, S., Yeh, P.J -F., Wahr, J. and Famiglietti, J . (2006) A comparison of terrestrial water storage variations from GRACE with in situ mea surements from Illinois. Geophysical Research Letters, vol. 33, article L16401, DOI: 10.1029/2006G L026962.

Swenson, S.C. and Milly, P.C.D. (2006) Climate model biases in sea sonality of continental water storage revealed by satellite gravimetry. Water Resources Research, vol. 42, no. 3, article W03201, DOI: 10.1029/2005WR004628.

Syed, T.H., Famiglietti, J.S., Chen, J., Rodell, M., Seneviratne, S.l., Viterbo, P. and Wilson, C.R. (2005) Total basin discharge for the Amazon and Mississippi River basins from GRACE and a land-atmosphere water balance. Geophysical Research Letters, vol. 32, article L24404, DOI:10.1029/2005G L024851.

Tapley, B., Ries, J., Bettadpur, S., Chambers, D., Cheng, M., Condi, F., Gunter, B., Kang, Z, Nagel, P., Pastor, R., Pekker, T., Poole, S. and Wang, F. (2005) GGM02 - An improved Earth gravity field model from GRACE. Joumal of Geodesy, vol. 79, no. 8, pp. 467-478, DOI: 10.1007/s00190-005-0480-z

Tapley, B.D., Bettadpur, S., Ries, J.C., Thompson, P.F., and Watkins, M.M. (2004b) GRACE measurements of mass variability in the earth system. Sc ience, vol. 305, no. 5683, pp. 503-506, DOI: 10.1126/sc ience.1099192

Tapley, B.D., Bettadpur, S., Watkins, M., and Reigber, C. (2004a) The Gravity Recovery and Climate Experiment: mission overview and early results. Geophysical Research Letters, vol. 31, article L09607, doi:10.1029/2004G L019920

Thompson, P.F., Bettadpur, S.V., and Tapley, B.D. (2004) Impact of short period, non-tidal, temporal mass variability on GRACE gravity estimates. Geophysical Research Letters, vol. 31, article L06619, DOI: 10.1029/2003G L019285.

Velicogna, I., and Wahr, J. (2005) Greenland mass balance from GRACE. Geophysic al Research Letters, vol. 32, L18505, DOI: 10.1029/2005GL023955

Velicogna, I., Wahr, J., Hanna, E., and Huybrechts, P. (2005) Short term mass variability in Greenland from GRACE. Geophysical Research Letters, vol. 32, a ricle L05501, DOI: 10.1029/2004G L021948

Vespe, F. and Rutigliano, P. (2005) The improvement of the Earth gravity field estimation and its benefits in the atmosphere and fundamental physics. Advances in Space Research, vol. 36, no. 3, pp. 472-485, DOI: 10.1016/j.a sr.2005.04.055.

Visser, P.N.A.M. (1999) Gravity field detemination with GOCE and GRACE. Advances in Space Research, vol. 23, no. 4, pp. 771-776.

Wahr, J., Molenaar, M., and Bryan, F. (1998) Time variability of the Earth's gravity field: Hydrologic al and oceanic effects and their possible detection using GRACE. J oumal of Geophysical Research (Solid Earth), vol. 103, no. B12, pp. 30205-30230, DOI: 10.1029/98J B02844. 
Wahr, J., Swenson, S., and Velicogna, I. (2006) Accuracy of GRACE mass estimates. Geophysical Research Letters, vol. 33, article L06401, DOI: 10.1029/2005G L025305

Wahr, J., Swenson, S., Jotnicki, V., and Velicogna, I. (2004) Time-variable gravity from GRACE: first results. Geophysical Research Letters, vol. 31, article L11501, DOI: 10.1029/2004G L019779

Winsemius, H.C., Savenije, H.H.G., Gerrits, A.M.J ., Zapreeva, E.A., and Klees, R. (2006a) Comparison of two model approaches in the Zambezi river basin with regard to model reliability and identifiability. Hydrology and Earth System Sciences, vol. 10, pp. 339-352.

Winsemius, H.C., Savenije, H.H.G., van de Giesen, N.C., van den Hurk, B.J .J .M., Zapreeva, E.A., and Klees, R. (2006b) Assessment of Gravity Recovery and Climate Experiment (GRACE) temporal signature over the upper Zambezi. Water Resources Research, vol. 42, article L12201, DOI:10.1029/2006WR005192

Woodworth, P.L. and Gregory, J.M. (2003) Benefits of GRACE and GOCE to sea level studies. Space Science Reviews, vol. 108, no. 1-2, pp. 307-317, DOI:10.1023/A:1026179409924

Wu, X., Heflin, M.B., Ivins, E.R., a nd Fukumori, I. (2006) Sea sonal a nd intera nnual global surface mass variations from multisa tellite geodetic data. J oumal of Geophysical Research (Solid Earth), vol. 111, no. B10, article B09401, DOI:10.1029/2005J B004100 